\title{
Taxonomy and evolution of the Triassic conodont Pseudofurnishius
}

Pablo Plasencia, Francis Hirsch, Jingeng Sha, and Ana Márquez-Aliaga

Acta Palaeontologica Polonica 60 (2), 2015: 385-394 doi: http://dx.doi.org/10.4202/app.2012.0048

Pseudofurnishius is a late Anisian (Pelsonian)-early Carnian (Cordevolian) conodont genus of gondolellid stock, characteristic for the Sephardic Province and restricted to the "Southern Tethys" region of the northern margin of Gondwana. Its most commonly found species, Pseudofurnishius murcianus, appears at the base of the Ladinian (Fassanian). The Ladinian material of Spain reveals its ontogeny characterised by initial lateral protrusions from the carina that may develop first mono-platform and later bi-platform units, finally evolving into elaborated multi-denticulated forms. The late Anisian-early Carnian phylogenesis of Pseudofurnishius priscus $\rightarrow$ P. shagami $\rightarrow$ P. murcianus is proposed. At the end of the Ladinian, Pseudofurnishius expanded to the entire "Southern Tethys" shelf and into Cimmerian terranes that drifted away from northern Gondwana, now accreted to Eurasia, such as the Sibumasu terrane (Southwest China-Malayan Peninsula).

Key words: Conodonta, Pseudofurnishius, taxonomy, evolution, Triassic, Sephardic Province.

Pablo Plasencia [pablo.plasencia@uv.es] and Jingeng Sha [jgsha@nigpas.ac.cn ], State Key Laboratory of Palaeobiology and Stratigraphy, Nanjing Institute of Palaeontology and Geology. 39 East Beijing Road, 210008 Nanjing, China; Francis Hirsch [francishirsch@gmail.com], Laboratory of Geology, Naruto University of Education, Naruto, 772-8502, Japan; Ana Márquez-Aliaga [ana.marquez@uv.es], Departmento de Geología e ICBiBE, Universidad de Valencia, Dr. Moliner, 50 Burjassot, 46100 Valencia, Spain.

This is an open-access article distributed under the terms of the Creative Commons Attribution License (for details please see creativecommons.org), which permits unrestricted use, distribution, and reproduction in any medium, provided the original author and source are credited. 
Fof Full text $(528.6 \mathrm{kB})$ 